\title{
A INTERACÃO ENTRE O CRESCIMENTO E O DESENVOLVIMENTO
}

Arnaldo Augusto Franco de Siqueira ${ }^{1}$

SIQUEIRA, A. A. F. A Interação entre o Crescimento e o Desenvolvimento. Rev. Bras. Cresc. Des. Hum. If 2): 1991.

\section{RESUMO}

A importância do estudo do processo de crescimento e desenvolvimento deve-se ao falo de que a forma como esse processo se realiza pode ser usada como um indicador positivo de saúde. O estudo do crescimento das crianças está ligado, desde seus primórdios, às Ciências Naturais e à Matemática; já o desenvolvimento passou a ser objeto de interesse das Ciências Humanas. Assim, o estudo do crescimento e do desenvolvimento envolve profissionais de formação diferente, que utilizam instrumental diferente. Há uma multiplicidade de condições que interferem, umas, no ritm o de crescimento; outras, no processo de desenvolvimento ou em ambos os processos; essas interferências podem ser de natureza biológica ou psicossocial. Tudo isso denotando que o crescimento e o desenvolvimento, enquanto campo de conhecimento, configuram uma interdisciplina. $\mathrm{O}$ avanço do conhecimento dependerá de interações entre disciplinas ligadas à Biologia, como a Medicina e a Nutrição, ou às Ciências Humanas, como a Sociologia e a Psicologia, e mesmo a áreas que, per si, já são interdisciplinas, como a Saúde Pública.

São apresentados exemplos de interacóes entre crescimento e desenvo1vimento, tirados da prática profissional do acompanhamento de crianças Adias, com a finalidade de suscitar reflexões e demonstrar a import neia da abordagem multidisciplinar do crescimento e do desenvol vimento.

A importancia, cada vez mais reconhecida, de se estudar o processo de crescimento e desenvolvimento, além do interesse especifico/profissional que possa despertar, reside no flato de que a forma como esse processo se realiza pode ser utilizada como um indicador positivo de saúde. Assim, ao invés de medir saúde pela sua falta (através dos coeficientes de morbidade ou mortalidade, por exemplo), parte-se do pressuposto de que quanto melhor, em um dado grupo social, o conjunto das crianças consegue expressar o seu potencial de crescimento e cumprir as etapas de seu desenvolvimento, tanto melhores deverão ser, nesse grupo, as condições de saúde.

Tradicionalmente, desde os primeiros estudos de que se tem notícia, a partir do século XVIII, o crescimento das crianças sempre esteve ligado às Ciências Naturais e à Matemática Aliás,

* Palestra preferida no Seminário “Encontro sobre Creches”, promovido pelo CDH e pela Faculdade de Saúde Pública/USP, em São Paulo, em outubro/86.

1 Professor titular do Departamento de Saúde Materno-Infantil da Faculdade de Saúde Pública/USP - Av. Dr. Arnaldo, 715 - CEP 01255 - São Paulo - SP - Fone. (011) 881-2451. 
boa parte do instrumental estatístico ainda hoje em uso, como as medidas de tendência central e a técnica de correlação, foi desenvolvido para solucionar questões metodológicas de estudos de crescimento.

Já o estudo do desenvolvimento passou, pouco a pouco, a ser de interesse para a área de Ciências Humanas, estando mais afeito às disciplinas da Psicologia e da Educação.

Nesse caminhar - nem sempre necessariamente paralelo por interessar profissionais de formação diferente, por utilizar instrumental diferente, por buscar talvez objetivos diferentes e por ater-se a valores e formas de avaliação ao menos aparentemente distintos - é, à primeira vista natural justificar a relativamente pequena interação entre essas duas áreas de atuação.

No entanto, se levarmos em conta o falo de que o crescim nto e o desenvolvimento estão ocorrendo simultaneamente nos indivíduos-mesmo ressalvando etapas, velocidades, carac $\wedge \mathrm{T}$ edsticas absolutamente particulares que cada aspecto pode apresentar-, torna-se necessário buscar algumas explicações para essa dicotomia entre esses dois aspectos do processo mais geral.

Ao reconhecer a multiplicidade de condições que podem interferir no evolver do crescimento da criança ao lado de outras que poderão favorecer, dificultar ou mesmo impedir seu desenvolvimento e, de outras ainda, que podem interferir a um tempo no crescimento e no desenvolvimento; ao reconhecer a diversidade dessas condições, que podem ser, umas, de natureza principalmente biológica, outras, predominantemente social ou, ainda, essencialmente psicológicas; ao perceber, enfim, que certas condições podem apresentar a um sé tempo uma natureza biológica e social, por exemplo, é que podemos dar-nos conta de que o crescimento e o desenvolvimento, enquanto campo de conhecimento, configuram claramente uma interdisciplina em que o avanço científico deverá depender de interações entre disciplinas várias, das quais podemos citar algumas mais ligadas à Biologia, como a Medicina, e a $\mathrm{Nu}^{\wedge}$ Trição, ao lado de outras das Ciências Humanas, como a Sociologia e a Psicologia, e outras que são, em si mesmas, interdisciplinar, como a Saúde Pública.

Existe, pois, toda uma dificuldade que perpassa uma série de questões conceituais básicas próprias das disciplinas envolvidas, a necessidade de buscar linguagens comum a uma metodologia que, sem desrespeitar essas questões básicas próprias de cada ramo do saber, possa construir um instrumental suficientemente simples e sensível para apreender não apenas as particularida- des de cada aspecto do processo, mas também as interações entre 0 crescimento e 0 desenvolvimento, no contexto social em que se desenrolam.

Serão apresentados aqui alguns exemplos de interações, alguns pontos ainda pouco claros e que poderão ensejar discussões especialmente importantes na medida em que se envolvam, nessa reflexão, profissionais de formações diversas.

Um bom exemplo, para começar, pode ser o do retardo de crescimento de crianças nos primeiros anos de vida. Deixando de lado todo um conjunto de retardos devidos a defeitos metabólicos e glandulares (não por não serem importantes, mas por serem devidos a distúrbios específi$\cos$ ), os retardos de crescimento, que ocorrem antes das crianças completarem dois anos de idade, têm sido consistenternente descritas, em nosso meio, e associados à desnutrição protéicoenergética, na maioria das vezes.

Esse falo é bastante evidente nos estratos sociais menos favorecidos ou nas classes sociais mais baixas, e sua explicação parece óbvia. Esses segmentos da população não conseguem adquirir o mínimo do que tem sido chamado de "bens fundamentais" que garanta a expressão adequada do potencial para o crescimento.

Ocorre que ao lado de um número expressivo de crianças com evidentes retardos pônderoestruturais coexiste, nesses segmentos da sociedade, um número não menos expressivo de crianças que seguem crescendo satisfatoriamente, mesmo quando submetidas, ao menos no que é possível medir, às mesmas condiçõs desfavoráveis que as demais crianças.

Além disso, também nas chamadas classes média e médiaalta atendidas em consultório, a grande maioria dos retardos de crescimento ocorrem nos dois primeiros anos de vida e ainda não se chegou ao ponto de afirmar haver menor disponibilidade de alimentos para as classes mencionadas.

Esses retardos não podem ser debitados à desnutrição, por não haver essa carência alimentar e nem mesmo outros sinais c]ínicos de desnutrição.

Numa tentativa, imperfeita porque superficial, de buscar explicação para esses casos - ressalvando, ainda, o não encontro de condições clínicas como infecções urinarias, cardiopatias e outras afecções que poderiam justificar esses retardos -, algumas características das famílias se repetem com grande frequência.

Assim, tais crianças muitas vezes são o primeiro filho de um casal em que quase sempre a mãe e, frequentemente, também o pai são ansiosos, inseguros, excessivamente preocupados com a saúde e o "desempenho" do filho. Essas crian- 
ças são hiperativas, dormem pouco, têm mais cólicas, apresentam resfriados e outras infecções respiratórios, de pequena gravidade, com maior frequência.

Muitas dessas famílias não são as chamadas nucleares típicas e quase sempre moram na mesma casa com vezes maternos) da criança.

Boa parte dessas mães é muito jovem e trata seus bebes numa postura que eu chamo de rigidez desfibrada, em que todo um programa de vida rigidamente delineado é executado de forma rigidamente permissiva, e as mães se consomem aumentando sua culpa e sua ansiedade^/insegurança, ao emitir um sem-número de nãos imediatamente desrespeitados pela criança.

A hora da comida é quase sempre grotescamente infernal; a criança despoticamente se nega a colaborar com toda uma encenação cada vez mais complexa e emocionalrnente carregada que, muitas vezes, acaba em ameaças e mesmo agressões. Essa criança é capaz de sair do campo de batalha e bater um bom prato de arroz, feijão e ovo na casa da vizinha

Outra parcela desses casos de retardo relaciona-se a uma postura familiar que procura, a qualquer custo, resguardar o pimpolho dos "traumas" (que é como consideram as situações de oposição à vontade da criança). A criança não deve ser contrariada para não ser "traumatizada" e, ai, o equilíbrio da dieta fica a critério de um ser ainda irracional (mas sem o conhecimento instintivo dos demais mamíferos). Invariavelmente, ao indagar por que uma criança vive à custa de chocolate, pipoca, batata frita e Tang Limão, a mãe diz: “Mas, doutor, é o que ele quer!”. E assim, a responsabilidade é passada para a criança.

Pode-se afirmar que tais casos, lamentavelmente cada vez mais frequentes, poderiam ser muito melhor trabalhados em interdisciplina, ou seja, em equipe da qual participariam outros profissionais além do pediatra, com uma contribuição que seja, a um sé tempo, específica de sua área de atuação e que busque a criação de uma metodologia comum para o seu manejo. Podese também considerar que estas situações, aqui descritas, são igualmente importantes e frequentes na rede de serviços; talvez a pressão assistencial não permita à equipe de saúde sequer 0 seu reconhecimento.

Que outra explicação, além de distúrbios afetivos, serviria melhor para caracterizar estes quadros de retardos, até mesmo severos do crescimento? É preciso salientar que não se está referindo aos casos evidentes de retardos do crescimento como uma faceta das privações afetivas e maus tratos infligidos às crianças por seus guardiões. Não há, aqui, ao menos consciente- mente, nenhuma intenção de fazer mal à criança; ao contrário, parece muitas vezes que as mães aqui mencionadas levam ao exagero sua percepção do que sejam os cuidados e as preocupações maternais.

Outros exemplos, talvez menos felizes, de interação entre 0 aspecto psicológico e 0 biológico poderiam ser encontrados na prática Sabe-se que a ofiologia dos retardos do crescimento intrauterino é conhecida em cerca de um terço à metade dos casos, no máximo.

A todos aqueles 50 a $70 \%$ de casos, sem etiologia conhecida, os médicos chamam (muito candidamente) de idiopáticos, o que significa dizer simplesmente que não se lhes encontrou uma causa organica conhecida.

Não seria espantoso, para nós, reconhecer um dia alguma interação entre o aspecto psicológico e o organico da gestante, ao menos em certas situações especiais, para explicar ao menos uma parte desses casos.

Porém, além de buscar uma influência psicológica sobre o crescimento, talvez também valesse a pena mencionar situações em que, de forma manifesto ou subreptícia, o contrário também pudesse estar ocorrendo.

Seria o caso de buscar exemplos de interações entre tipos constitucionais e atitudes e posturas da criança frente a estímulos e exigências que a rodeiam. A criança que, por qualquer razão, passa a ganhar peso excessivamente escolhe atividades que menos exijam dela em dispêndio energético, ou crianças com tendência ou levadas a ter uma menor atividade passam a ganhar muito peso? A criança "muito tranquila" não seria um exemplo de falta de solicitação maternal ou ambiental? E, assim acostumada, não teria/desenvolveria certas características de relação com o mundo que influenciariam até no seu crescimento?

Seria lícito também citar os problemas do crescimento na adolescência.

Após uma longa fase de crescimento pouco intenso (e cuja velocidade tende a diminuir) e que vai dos três anos Até uma idade variável (entre 10 a 12 ou 13 anos para as meninas e 12 a 14 ou 15 anos para os meninos) as crianças entram no que se convencionou chamar de "estirão da adolescência”, período esse que dura de dois a três anos e no qual, de um crescimento de cerca de dois a três $\mathrm{cm} / \mathrm{ano}$, as crianças passam a crescer a uma velocidade de 10 e até 15 crn/ano.

Durante esse período ocorrem também outras modificações das quais a mais importante é a maturação sexual, nitidamente marcada pela menarca, no caso das meninas, e sem qualquer marcador para os meninos. É óbvio que, além desse crescimento ffsico (ou até mesmo por cau- 
sa dele), outras importantes mudanças também devem ocorrer no plano psicológico, desde o alcançar do estágio operatório formal de Piaget, em que $\mathrm{o}$ adolescente (nem todos, é forçoso reconhecer) atinge a capacidade de pensamento hipotético-dedutivo e, mais do que isso, é levado a (ou impedido de) abrir seu próprio espaço no mundo dos adultos.

E, assim, uma fase da vida caracterizada por uma variedade de modificações de tamanho, de mudanças de relações corporais, de alterações hormonais, de mudança de papéis a serem desempenhados, tudo isso com um timing próprio para cada pessoa, e que deveria ser uma etapa positiva, acumulativa, de acumulação de massa, de capacidade física e intelectual, pode transformar-se, ao menos em parte, por desconhecimento do próprio processo, seja da parte dos interessados, seja dos pais e também dos profissionais envolvidos nesse acompanhamento, em uma guerra psicológica em que não há vencedores.

Se adequadamente esclarecido, um menino de 14 anos, baixo em relação a seus pares por ser um adolescente "tardio", ainda atrasado em todo esse processo, com características corporais e maturacionais de menino, mas com capacidade intelectual e convivendo com outros rapazes de 14 anos que já poderão até ter completado esse ciclo, pode perfeitamente escapar relativamente ileso de toda uma pressão para considerá-lo anormal. Da mesma forma, um menino de 13-14 anos "precoce", isto é, já no final de seu processo de crescimento e maturação, poderá ser esclarecido de que já está praticamente parando de crescer e não se tornará em gigante anormal e terminará não sendo mais diferente de seus pares do que há 3-4 anos, antes do início de toda essa "confusão".

No entanto, o que se vê é um grande número de adolescentes (meninos e meninas) tardias, apressadamente rotulados de anormais, de portadores de deficiências endocrinológicas e hormonais, e assim tratados.

Nada indica que tudo isso venha a robustecer a auto-estima, a contribuir para que o individuo tenha de si mesmo uma imagem favorável, e facilitar, enfim, sua passagem para a adultícia Quanta timidez e insegurança aí se originam!

De outra parte, tem se visto não poucos adolescentes "precoces", com sérios problemas de coluna, posturais, etc., adquiridos na tentativa vã de parecerem mais baixos, ou talvez até por inadequação do mobiliário escolar, que padroni- za (até na carga de ati^${ }^{\wedge}$ vidade física), criaturas que estão vivendo momentos muito distintos desse estirão. Quantas meninas exacerbam cifoses dorsais na tentativa, igualmente vã, de disfarçar um crescimento mamário julgado excessivo apenas por ocorrer mais cedo que o de suas colegas!

No entanto, o que se costuma dizer é que adolescente não tem problemas (talvez por uma comparação superficial entre as elevadas mortalidades dos primeiros tempos de vida e as que se verificam entre 10 e 19 anos, inegavelmente baixas). Quantos desses aspectos, que aqui se está chamando de "processo normal de crescimento na adolescência”, não poderão, se sua importancia não for detectada, produzir ou agravar situações existentes, quadros até complexos e graves de distúrbios afetivos que poderão interferir negativamente no desenvolvimento do processo mais geral?

Aqui, pode-se ver outra vez um situação de interdisciplina em que a abordagem simultanea, específica e, ao mesmo tempo, globalizadora de uma equipe multidisciplinar poderia ser extremamente vantajosa para todos: profissionais, adolescentes, suas famílias e a própria sociedade.

Cumpre deixar claro, para finalizar, que não houve a preocupação em ater-se a aspectos do que é francamente patológico, seja do lado biológico, como os nanismos, seja do lado psicológico, como os problemas levantados, por exemplo, por Spitz em creches, em que a carência afetiva era causadora de retardos, doença e morte, ou mesmo nos casos de hospitalismo, que podem acabar por levar a consequiências gravíssimas. Se, porém, situações tão rotineiras e aparentemente desinteressantes, como o acompanhamento de uma criança sadia, podem servir de reflexão para toda essa questão da interação entre o biológico e o psicológico, não resta qualquer dúvida de que se deva ter todo o cuidado de, ao menos, procurar garantir, especialmente no primeiro e no segundo anos de vida, para todas as crianças eventualmente ao nosso alcance-nossos filhos, a clientela dos Centros de Saúde, os pacientezinhos internados sob nossos cuidados, as crianças das creches, a criançada na pré-escola, os filhos da vizinha—alguém coisa ao mesmo tempo tão simples e tão importante porque indispensável que é o afeto, o amor.

Devemos aprender a trabalhar em equipe. Nesse trabalho sejamos, porém, apesar de cada vez mais profissionais, sempre que possível, um pouco menos especialistas e cada vez mais humanos. 